\title{
A Case Study Analysis on E-agriculture (e-velanmai): An ICT based Technology Transfer Model in Agriculture in Tamil Nadu state, India
}

\author{
P. Anbarasan* \\ Department of Agricultural Extension and Communication, School of Agricultural \\ Innovations and Advanced Learning (VAIAL), Vellore Institute of Technology(VIT), \\ Vellore, India \\ *Corresponding author
}

A B S T R A C T

\begin{tabular}{|c|}
\hline Keywords \\
\hline $\begin{array}{l}\text { e-velanmai, Case } \\
\text { study, Information } \\
\text { and Communication } \\
\text { Technology (ICT), } \\
\text { Technology } \\
\text { Transfer, Extension, } \\
\text { Agriculture, River } \\
\text { sub basins }\end{array}$ \\
\hline Article Info \\
\hline $\begin{array}{l}\text { Accepted: } \\
\text { 12 December } 2020 \\
\text { Available Online: } \\
10 \text { January } 2021\end{array}$ \\
\hline
\end{tabular}

Introduction

"Access to Information and Communication Technologies (ICTs) implies access to channels and modes of communication that are not bound by the barriers. New forms of social organization and of productive activity emerge, which if nurtured, could become transformational factor as important as the technology itself".

The new paradigm of agricultural
In this modern era e-velanmai is the enhanced version in satisfying the farmer agro technological information needs. The innovative technological boons like Computer, Internet, and Mobile will be helpful for the farmers to get consultancy for their farming issues from various eminent scientists. The e-velanmai is definitely a promising scheme for time shrinking in answering farm related queries.The present study was conducted in Tamil Nadu State of India. Aliyar and Palarriver sub basins of Coimbatore and Tiruppur districts were selected for identifying the respondents. Case study methods were used for the data collection and number of 10 cases were identified for knowing the effectiveness of e-velanmai.e-velanmai was evaluated as an effective means to transfer agro technologies to farmers. This is considered to be an effective approach of technology transfer to farmers by agricultural experts. 
developing the capacity to generate, absorb, disseminate and protect knowledge and to exploit knowledge as a powerful tool to derive societal transformation. The background report of "working Group on Information Technology for the Masses" declared: "It is firm view of the Government that if any technology can create new opportunities to bridge the gap between information haves and have-nots in the present times, it is Information Technology". (GOI, 2000). It is being increasingly felt that ICTs can be major vehicle for all round socioeconomic development. In other words, ICTs can play spectacular role in the societal transformation to realize the concept of "Knowledge Society" in the Indian context. ICTs when used as a broad tool for amalgamating local knowledge communities with the scientific Knowledge, heralds the formation of the class of society, which is nothing but "Knowledge Society".

\section{Realizing the Knowledge Potential}

The societal transformation, using information as a powerful tool, is possible only when full potential of knowledge is realized. The societal transformation in India can be realized, only when the knowledge and information are effectively harvested for overall agricultural and rural development.

Being an agriculturally rich country, India cannot overlook the field of agricultural development as the main domain of societal transformation. Here comes the enormous potential of the ICTs that has to be harnessed for overall agricultural development in particular and hence for societal transformation in general. The development of precision farming in countries of the North emphasizes knowledge - intensity and hence the new agricultural paradigm in India will have to be recast to take advantage of the knowledge availability to achieve multiple goals: of income, food, jobs, etc.

To put it in simple words knowledge society is one, which uses knowledge through all its constituents and endeavors to empower and enrich its people. It has the capacity to generate, absorb, disseminate and protect knowledge and also use it to create economic wealth and social good for all its constituents. It uses knowledge as a powerful tool to drive societal transformation.

Producers can even have a competitive edge over larger operations. When knowledge is harnessed by strong organizations of small producers, strategic planning can be used to provide members with least cost inputs, better storage facilities, improved transportation links and collective negotiations with buyers (Swaminathan, 1993).

\section{ICT for meeting the Challenges of Globalization}

The changes in global market because of ratification of World Trade Organization (WTO) Agreement are likely to produce some big changes for small producers. Therefore, they need to understand the implications of WTO agreement and global market situations to make better decisions about timing, marketing and management.

The extension system cannot remain passive actor in the global market economy. Information Technology provides the data base management systems, expert systems and site specific information systems, which would be helpful to the small producers in realizing the comparative advantage of their production systems and also in marketing management. Much talked about management development (MADE) can be realized using Information Technology (Zijp, 1994).

Information Technology can also play an 
important role in bringing about sustainable agricultural development. For this the organic cultivation practices together with the traditional knowledge can be documented using the ICTs. India, as a nation can create, what is known as, a Traditional Knowledge Digital Library (TKDL) which would serve a bigger purpose in providing and enhancing her innovation capacity. Further, this could integrate widely scattered and distributed references on Indian Indigenous Technical Knowledge (ITK) systems in a retrieval form. Thus ICTs could act as the bridge between the traditional and modern knowledge systems. (Jones, 1997).

\section{Areas of ICTs Convergence}

Use of ICTs in support of agricultural and rural development, applications fall into five main areas, as given by Don Richardson (FAO, 1996). These are economic development of agricultural producers, community development, research and education, small and medium enterprises development, and media networks.

Rural communities and small-scale agricultural producers are deeply affected by global economic, environmental and political forces. Using the ICTs, knowledge can be harnessed by strong organization of small producers, which will lead to the overall development of the flow of information at various stages. It is an inexpensive way to communicate and access global information. Well-organized local user groups and farmers' organizations can easily manage local Internet services. Information and analyses can be tailored to local, regional and national knowledge and communication needs and realities.

Modern Information Technologies can be used for the community development applications as well. When systematically applied and adapted to conditions of rural communities, Information Technology can be used for rural communication to increase participation, disseminate information and share knowledge and skills for community development. (Shaik, 2005).

\section{About e-velanmai (e-agriculture)}

It is an ICT based demand driven and participatory technology transfer model in agriculture to provide timely agro advisory services by a multidisciplinary team of agricultural scientists to the farmers using ICT tools (Digital camera, computer, internet, mobile phone etc.) through a Field Coordinator (FC)/volunteer (farmer) on need basis(Karthikeyan, 2009).

It is a sustainable approach of technology transfer for enabling scientific farming and enhances farm productivity. It is referred as demand driven and participatory technology transfer model because:

Farmers pay a membership fee based on the farm size owned by them to avail the extension services under e-velanmai as an indicator of their participation in the system of technology transfer.

Scientists attend the farmers queries based on their call (demand) or need and hence it is demand driven for technical advice or scientific farming.

It is also believed to be sustainable approach of extension as it facilitates the farmers to adopt the 'e-velanmai' model for technology access in the long run even after the project period (2012). The membership fees collected will be utilized for managing the sustainability of the process.

The 'e-velanmai' was evolved from a pilot tested public model initiated during July 2007 
to a paid model or private model during October 2008. In order to enhance the participation of farmers in scientific farming and to have sustainability of the scheme, paid model of e-Velanmai was conceived and introduced in three sub basins namely, Palar, Aliyar and Varahanadhi through WUA functioning in these command areas. (http//www.evelanmai.com).

\section{Research Methodology}

\section{Selection of the District}

This study was conducted in Coimbatore and Tirupur districts of Tamil Nadu state. Coimbatore and Tirupur districts were selected due to the reason that the action research project, "e-velanmai" which was started during July 2007 and it is being implemented in these two districts with the support of the World Bank aided TNIAMWARM project sponsored by the government of Tamil Nadu. Through this project "e-velanmai" aims to provide quality, timely, farm specific scientific advice with the support of ICT tools, agricultural scientists and to the needed farmers at their respective farm gate.

\section{Description of the study area}

\section{Coimbatore district}

Coimbatore district lies in the Western part of Tamil Nadu, part of the Kongu Nadu region. The district borders with Palakkad district of Kerala in the West, Nilgiris district in the North, Erode district in the North East and East, Idukki district of Kerala in the South and Dindigul district in the south east.

Coimbatore district is located in the northern region of Tamilnadu state which is exactly located in between $11^{\circ} 15^{\prime}$ North latitude and $77^{\circ} 19^{\prime}$ East longitude with an average sea level (MSL) of 432-12 m.Coconut, Banana, Maize, Sugarcane, Tapioca are the major crops cultivated in the Aliyar and Palar sub basins of this district. These villages have three different types of soils normally black loam, red loam and red sandy soils. The percentages of red loam, red sand and black loamy soils are are 15\%, 10\% and $75 \%$ respectively..(www.coimbatore.nic.in).

\section{Tiruppur district}

Tiruppur district lies on the western part of Tamilnadu bordering the Western Ghats and hence the district enjoys a moderate climate. The district is surrounded by Coimbatore district in the west, Erode district to the Northeast and Karur district in the east and Dindigul district in the south east. To the south the district is surrounded by Kerala state (Idukki district).Tirupur district is located in the northern region of Tamilnadu state which is exactly located in between $11^{\circ} 18^{\prime}$ North latitude and $77^{\circ} 25^{\prime}$ East longitude.Coconut, sugarcane and banana were the major crops grown in the sub basin of this district. Villages in the Tirupur district have three different types of soils namely loamy soil, red soil and black soil and the percentages of black soil, red soil and loamy soil were $50 \%$, $30 \%$ and $20 \%$ respectively. In general, the soil in and around the city is fertile and good for agricultural purposes.(www.tirupur.nic.in)

\section{Selection of River Sub basins}

This study was conducted in the two canal command areas of Palar and Aliyar sub basins of Tiruppur and Coimbatore districts respectively. The pilot testing of the evelanmai model has been attempted in these sub basins and hence the selection of the study area was done accordingly.To document the experiences of farmers in accessing agricultural advices through evelanmai, a sample of 5 cases from each sub 
basin, totally 10 cases were identified to represent the typicality of the case in the region.

\section{Documentation of the Farmers Experience with e-velanmai approach of extension}

Case study is an effective tool to analyze the shrewdness of the e-velanmai scheme among the farmers. Case study further paves way to find out the real time problems faced by the farmers and helps to depict that in what extent that problem can be overcome, through the benefits of e-velanmai method. It further extends its service as a mirror to find out the innovative ideas regarding the development of the scheme. The documentation of the farmers experience with "e-velanmai", through case studies will be helpful in understanding the way these initiatives have been designed, implemented and received by the farmers.

\section{Case study No: 1}

K.RathinasamyGounder, (S/o.KulandaivelGounder), aged 55 years is a leading marginal farmer with 4 acres of gardenland at Kariyanchettipalayam village, Kambalapatti Water Uses Association, Anamalai Block, PollachiTaluk. He is being in the cultivation coconut for more than 10 years. Since he is an e-velanmaifarmers from June' 08 onwards, his farm is covered under the scheme of e-velanmai for technical advice. Though he got a very good experience in coconut cultivation, he encountered the severe damage in the trunk of the tree like bore holes and oozing of liquids. The problem has been brought to the notice of field coordinator by the farmer. The field coordinator visited the field, by seeing the symptoms he confirmed it as the damage due to red palm weevil. For further confirmation and recommendation digital images have been recorded and forwarded to the subject matter specialist (e-velanmai) in TNAU. The scientists confirmed that the coconut trees were infested with red palm weevil (during the month of Feb`10). The symptoms recorded by them were,

1. Bore holes in the trunk of the tree

2. Reddish brown oozing from the bore holes.

3. Central shoot shows sign of wilting

4. Insect excreta were observed around the bore holes.

Recommendations offered were: The infested portion should be scooped out. Pour one celphos (Aluminium Phosphide) tablets inside the bore holes. Plug the bore holes with cement.

The farmer appreciated the process of technology transfer through e-velanmai as it is very simple and useful, just by making a phone call he was able to solve his farm problems.

\section{Case study No:2}

Mr. C. Palanisamy, whose age is 53 is a leading farmer at MANNUR, village, Thimmankuthu Water Users Association, Pollachi block. He has 10 acres of garden land, cultivating coconut since from past 30 years. His farm had red soil and suitable for cultivation of cowpea and coconut. He has good contacts with extension agency and knowledge of handling ICT tools. He found that the fields were infected with Basal Stem End Rot disease. He was not assure of control measures. He took certain photographs containing symptoms and forwarded to scientist in CRS, Aliyar through email. The scientist after confirmation of the disease symptoms, recommended the control measures to farmer through email and the recommendations were as follows Making an isolation trench, 4 feet away from the trunk at the depth of 3 feet. Inside the trench apply Inorganic sulphur(sulphur dust) 200g/tree. 
Soil drenching with $1 \%$ Bordeaux mixture 40 lts/tree orTrunk injection with $3 \mathrm{ml}$ tridemorph (calaxin), make a hole of $10 \mathrm{~cm}$ on the trunk 3 feet above the ground level using auger and inject the above said chemical. Plug the hole with cement follow the procedure once in 3 months interval. Due to the quick access to the disease control measures the farmer was able to control the disease immediately. As the recommendations were on time through evelanmai, the farmer was appreciating the method of extension and its usefulness.

\section{Case study No:3}

Mrs. Nithya, aged 35, was one of the leading farmer in T. NallikoundanPalayam village cultivating banana in her 2 acres of land. In her field she encountered panama wilt. She applied many chemicals without consideration of our TNAU scientists. Disease was not controlled. The field cocoordinator visited and inspected the field he took some photographs and send to the TNAU scientists on the spot using lap top and modem. The scientist readily diagnosed the disease symptoms and recommended the management measures then and there.

Recommendations of the scientist were:

1. Remove the soil from the base of the pseudostem and expose tip of the corm.

2. Make a hole to a depth of $10 \mathrm{~cm}$ at 45 degree angle using $7 \mathrm{~mm}$ screw driver without affecting the growing portion.

3. Immediately Inject $3 \mathrm{ml}$ of $2 \%$ carbendazim.

Dissolve $2 \mathrm{~g}$ of carbendazim in $100 \mathrm{ml}$ water which gives $2 \%$. As the Information was accessed quickly in time, the farmer was able to control $80 \%$ of the plants from the disease.

\section{Case study No:4}

B. Narayanasamy, (S/o.Balasubramani,), aged 39 years and he is holding 3.5 acres of garden land. In his garden land he is being cultivating coconut for 15 years. He attached himself under e-velanmai scheme at December' 08. He used to attend technical seminars that have been organized under e-velanmai scheme. One of the seminars that have been organized is about coconut tonic root feeding. $\mathrm{He}$ implemented this technology in his farm and experienced better result. Some of the benefits of the coconut tonic root feeding are listed below,

Increases the yield in coconut by giving growth nutrients and growth hormones through root feeding.

It Improves no of nuts per tree

It improves chlorophyll content of the leaves It improves numbers of leaves per tree It controls coconut bud droppings It increases weight of the Copra It improves adverse climatic conditions, insect pests and diseases resistance to the tree It Increases other nutrient uptake of plant.

Farmer feels happy to be a member of evelanmai scheme as he enjoyed timely advice and savings in input use.

\section{Case study No: 5}

Mr. A.Kannappan, (S/o, Mr. AppachiGounder), aged 45 years having 8 acres of garden land at Sellandikoundanpudur village Devam Padivalasu Water Users Association, PollachiTaluk. His experience in farming is more than 18 years. He got the membership of the e-velanmai scheme at June' 08 . He has noticed brown discoloration in patches of the coconut tree husk and also button sheds. Because of this trees resulted in poor setting percentage. As he is an evelanmai member, he approached the field coordinators to help him in this regard.

Field coordinators acted swiftly and they took the photo of the symptoms and mailed that to 
TNAU scientists. After getting the reply mail from scientist saying recommendation for that particular disease, field coordinator gave the advice to farmer.

\section{Recommendations}

Name of the Pest : Eriophite mite

Adoption of phytosanitary measures in coconut gardens such as cleaning the crown of the palm, keeping the plantation clean and burning of all immature nuts fallen due to mite infestation.

Spraying bio pesticides on the bunches a) $2 \%$ neem oil - garlic emulsion $(20 \mathrm{ml}$ neem oil $+20 \mathrm{~g}$ garlic $+5 \mathrm{~g}$ bar soap in 1 litre water) . Emulsion has to be prepared on the same day of application itself. b) Other neem based pesticides at $0.004 \%$ (Azadirachtin). If the pesticide formulation contains $1 \%$ Azadirachtin, $4 \mathrm{ml}$ has to be used in 1 litre water. Wherever spraying is difficult root feeding may be resorted to with Azadirachtin $5 \%$ formulation $(7.5 \mathrm{ml}+7.5 \mathrm{ml}$ water $)$ or Azadirachtin $1 \%$ formulation $(10 \mathrm{ml}+10 \mathrm{ml}$ water).

Spraying has to be done 3 times a year December-February, April-June and September-October. While spraying, ensure that the spray fluid falls over the perianth region especially on button and tender nuts. On an average 1-1.5 litre spray fluid is required per palm. Care should be taken to harvest mature bunches before spraying.

Following palm health care practices also may be adopted.

Recycling of biomass generated within the coconut system by vermi compost method or by using lignin degrading fungus.

Raising of green manure crops in the coconut basins (like sunhemp, cowpea, calapagonium etc.) and incorporation into the soil in the basin itself, these act as mulch during summer and slowly decompose and provide nutrients when incorporated to soil.

Application of recommended dosages of fertilizers, in two split doses, as per the package of practices prevailing in the respective states.

Recommended level of irrigation during summer months i.e. 250-500 litres of water per tree per week (based on evapotranspiration in the given area).

Soil moisture conservation by following methods.

i. Burial of coconut husk in the basin.

ii. Mulching the basins ( $2 \mathrm{~m}$ radius) with coconut leaves/green manure / green leaf manure.

iii. Mulching with coir pith wherever available ( $2 \mathrm{~m}$ radius).

Farmer got precise advice at his farm gate within a short period of time, which eventually helped him to increase the yield and profit.

\section{Conclusion and Recommendations}

Agricultural and Rural Development is a complex endeavor. ICT Extension can't and should not be assumed to resolve the variety of agricultural and rural development problems, although it may serve in information coordination amongst relevant agencies. Enough ICT initiatives have been pilot tested in Indian context, so far. There is a need to look beyond the pilot testing of ICTs to evolve the proper extension efforts that harness ICTs. For this, there is need to incorporate the ICTs into structural and functional components of the extension organizations. However the formation of social capital and capacity building of farmers on using ICT tools can be achieved by deploying the services of agricultural 
extension officers of the state department of Agriculture. Hence without any additional cost this model of ICT enabled farming could be achieved at state level in Tamil Nadu and replicated in other states of India also as every state has got one or more state agricultural universities and research institutes.

\section{Study recommendations}

Efforts should be made to incorporate the Information Technology in all endeavors related to agricultural development. The organizations and departments concerned with agricultural development need to utilize the ICTs in realizing its potential and for speedy dissemination of information to the farmers.

Government at national and state level have to reorient their agricultural policies so that a full-fledged strategy to fully gear up the process of harnessing the potential of ICTs in overall agricultural development of the country.

It is recommended that the policy makers utilize the analysis of the ICTs projects carried out in the study for formulating a strategy for use of ICTs in agricultural development in the country.

The future ICT initiatives should make use of ICTs as both information gathering tool and information sharing tool. Imbalances between these two dimensions need to be checked in the early stages.

Efforts should be made to bring about user equity in future ICT initiatives by incorporating target specific information modules (targeted towards women farmers, youth etc.)

For effective delivery of ICT/ICTs services, people who demonstrate high orientation towards ICTs extension and faith in people should be preferred to man the services.
Intensive training on use of ICTs modules should be imparted to the persons to be recruited as interfaces (It should not necessary for the individuals to have professional degrees/ diplomas in computers.

Generating awareness about availability of ICTs services among young and middle aged farmers, is the first step to be considered in enhancing participation of farmers in IVT initiatives. The old farmers should be brought into the chain of ICT networks in the later stages of inception.

As it was found from the study, small and marginal farmers were using ICTs services, more emphasis should be given to provide more information relevant to the small and marginal farming systems.

It is recommended to develop strong interfaces at village level so that problem of computer illiteracy among farmers could be answered. User friendly software's and graphic interfaces and pictorial information are some of the ways to encourage the farmers in using ICTs services.

In areas where commercial farmers are prevailing, ICT services should be provide information on early disease/ pest warnings, question-answer services, cropping system and planning, best and latest package of practices of commercial crops, weather forecasting, soil testing and sampling, post harvest technology, input prices/availability, farm business information and crop insurance.

It is recommended that before initiating ICT services in any region, efforts should be made to develop medium to high level of farmer's faith in ICT functionaries and their goal commitment. It is also suggested that participatory Rural Appraisals and Rapid Rural Appraisal 
should be carried out to know about the information needs of farmers. In the process, farmers self-full-filling faith on each information service provided should be enhanced.

It is recommended that immediate efforts should be made to improve the connectivity aspects so as to establish village level kiosks in all the regions of country and also making it affordable and easy access among the farmers.

The apex bodies like ICAR, Directorate of Extension, State Agricultural Universities and Agricultural Commission need to develop a fullfledged strategy in promoting information access to farmers. This should be reflected in harnessing ICT in agricultural research, education and extension. There is need to encourage private sector for providing ICT services to farmers and develop a strong competition among them.

\section{References}

FAO. 1996. Suggestions for bridging the digital Divide. Rome. FAO Publications.

FAO, 1996.The internet and the rural development recommendation for strategy and the activity.Consultants report by D.Richardson. Rome.

Government of India Ministry of Information Technology(2000). "Working group on Information Technology for Masses", Background report. Online: http://itformasses.nic.in/vsitformasses/p agel.html.

Jones, Gwyn E.1997. The history, development, and future of Agricultural Extension in Improving Agricultural Extension- A reference manual by Burton E Swanson et.al., FAO, Rome publications.

Karthikeyan, C 2009. 'e-velanmai- An ICT based agro technology transfer model'. Key speaker paper presented in the eINDIA 09 International conference held during 26-29 August 2009 at Hyderabad.

Meera,N. Shaik and Anita Jhamtani 2005. Future projections of use of Information Technology in Agricultural Development in India.Indian Journal of Extension Education. 40(1\&2): 1-7.

Swaminathan, MS 1993 (ED). Information Technology: Reaching the Unreached Chennai: Macmillan India.

Zijp, W. 1994.Improving the Transfer and use of Agricultural Information: A guide to Information Technology.World Bank discussion Papers, 247, P 105.

\section{How to cite this article:}

Anbarasan, P. 2021. A Case Study Analysis on E-agriculture (e-velanmai): An ICT based Technology Transfer Model in Agriculture in Tamil Nadu state, India. Int.J.Curr.Microbiol.App.Sci. 10(01): 1688-1696. doi: https://doi.org/10.20546/ijcmas.2021.1001.197 